\title{
ANÁlisis de La CREación y MODIFICACIÓN DEL CONSEJO DE LA MAgISTRATURA DE LA REPÚBLICA ARgentina*
}

Pablo Ignacio Hunger ${ }^{(a)}$

ANALYSIS OF THE CREATION AND MODIFICATION OF THE COUNCIL FOR THE MAGISTRATE FOR THE REPUBLIC OF ARGENTINA

ANÁLISE DA CRIAÇÃO E MODIFICAÇÃO DO CONSELHO

DA MAGISTRATURA DA REPÚBLICA ARGENTINA

Fecha de recepción: 18 de septiembre de 2017

Fecha de aprobación: 15 de enero de 2018

Sugerencia de citación:

Hunger, P. I. (2018). Análisis de la creación y modificación del Consejo de la Magistratura de la República Argentina. Razón Crítica, 4, 163-194, doi: http://dx.doi.org/10.21789/25007807.1297

* El presente artículo obra como segmento primordial de la tesis (en producción) denominada de igual manera que será presentada para obtener la titulación de magíster en Administración Pública por la Facultad de Ciencias Económicas de la Universidad de Buenos Aires.

(a) Licenciado en Ciencia Política de la Universidad de Buenos Aires.

Presta servicios en la Dirección General de Reforma Política del Ministerio de Gobierno de la Ciudad Autónoma de Buenos Aires, Argentina hppolitica@gmail.com 


\section{R E S U M E N}

El presente documento dará cuenta de las modificaciones normativas (constitucionales e infraconstitucionales) que sufrió el Consejo de la Magistratura del Poder Judicial de la Nación con el objeto de justificar el impacto negativo que han tenido sobre la administración de justicia de la República Argentina. Dichas modificaciones han alterado el equilibrio republicano establecido explícitamente en la Constitución nacional, restringiendo el derecho de acceder a la justicia de cada argentino. El análisis que se efectuará a continuación se centrará en el plenario del Consejo de la Magistratura para explicitar cómo la injerencia del poder ejecutivo colisiona contra el equilibrio de poderes, resultando de ello una justicia dependiente.

PALABRAS CLAVE: república, equilibrio, administración de justicia. 


\section{A B S T R A C T}

This document will explain the normative changes (constitutional and infraconstitutional) suffered by the Judicial Council of the Nation's Judiciary in order to justify the negative impact they have had on the administration of justice in the Republic of Argentina. These modifications have altered the republican balance explicitly established in the National Constitution, restricting the right of access to justice by every Argentinean. The analysis that will be carried out next will focus on the plenary of the Judicial Council to explain how the interference of the Executive Power collides against the balance of powers, resulting therefore in a dependent justice.

\section{KEY WORDS: republic, balance, administration of justice .}

\section{R E S U M O}

O presente documento evidenciará as modificações normativas (constitucionais e infraconstitucionais) que o Conselho da Magistratura do Poder Judiciário da Nação sofreu para justificar o impacto negativo que aquelas produziram sobre a administração da justiça da República Argentina. Essas modificações alteraram o equilíbrio republicano explicitamente estabelecido na Constituição Nacional, restringindo o direito de acesso à justiça para cada cidadão argentino. A análise feita a seguir se concentrará no plenário do Conselho da Magistratura para explicar como a interferência do Poder Executivo colide com o equilíbrio de poderes, resultando numa justiça dependente.

PALAVRAS-CHAVE: administração da justiça, equilíbrio, república. 


\section{N T R O D U C C I Ó N}

La República y la democracia serán plenas cuando cualquier persona pueda explicarlas; cuando puedan ser transmitidas con escasas palabras y no sea costoso ni complejo hacer entender al prójimo qué implica cada concepto; cuando, en términos generales (educación, salud, derechos, bienes materiales, etc.), muchos no tengan poco ni pocos mucho. Este escenario permitiría a cualquier individuo saber qué es lo que le corresponde sencillamente por derecho y que no, de esta forma no serían tan cotidianas la demagogia, el engaño e, inclusive, la corrupción.

Para el ejercicio adecuado del poder que la sociedad ha delegado, se requiere de instituciones que lo encaucen a partir de una administración prudente y subordinada a las debidas normas, obligaciones y derechos de la población. Allí cobra vigor la administración pública, pues ella no es otra cosa que un sistema administrativo de regulaciones que establece las formas en las cuales los distintos poderes mantienen el orden que la sociedad requiere para alcanzar el bien comunitario.

La república es el inicio, el punto de partida. Marca el rumbo a través del cual el poder es dividido en partes iguales para lograr un equilibrio que proteja de su mal uso; la administración pública transforma ese concepto, mayormente abstracto, en herramientas tangibles, ordenadoras de la acción estatal. Requiere de estructuras e instituciones sólidas y eficaces para cumplir su misión, pues en caso contrario, los resultados conllevarán a una mala administración o una república falaz. Este escenario materializa desigualdades 
adversas a las garantías ciudadanas, vulnera la equidad social sobre empoderando y desprotegiendo a unos y otros. Una república fallida no tiene otra meta que el alejamiento del desarrollo sustentable.

El Estado será para algunos, no para todos, constituyendo a los primeros en ciudadanos, mientras que los segundos no podrán ser así denominados.

El presente artículo se adentrará en el estudio del Consejo de la Magistratura de la República Argentina al considerar que su rol dentro del poder judicial es vital para la consagración de la independencia judicial. Al partir de la concepción de una administración pública que comprende a la gestión de los tres poderes de gobierno, la prestación de una correcta administración de justicia (comprendida en ella), es un requisito ineludible en un gobierno democrático. Se define el concepto de justicia y se problematizan las modificaciones sufridas por el organismo considerando que han ido en detrimento de la garantía ciudadana de justicia y del equilibrio de poderes. A través de la comparación de las sucesivas leyes modificatorias, se buscará demostrar el aumento de la injerencia del poder ejecutivo sobre la administración judicial.

\section{La administración de justicia}

La democracia republicana implica el gobierno del pueblo, pues lo considera como el legítimo soberano para el ejercicio del poder. El pueblo como unidad no puede gobernar o, mejor dicho, no podría hacerlo como es debido si no cuenta con mecanismos de representación inclusivos que recojan los intereses mayoritarios y minoritarios. Lógicamente, el cumplimiento de los principios democráticos se vislumbra en la satisfacción de los intereses de la mayoría del pueblo, hecho que no implica la vulneración de los derechos de quienes, siendo parte de él, no comulgan con las autoridades gubernamentales. Una genuina democracia es alcanzada cuando existen mecanismos o sistemas de protección legales que abogan por un equilibrio en el ejercicio del gobierno.

Al hablar de sistemas o mecanismos, es preciso descender de la abstracción conceptual al plano material. La administración pública es definida aquí como el conjunto de procedimientos y reglamentos que establecen el modo del ejercicio del poder; es el conjunto de 
actividades administrativas que el Estado utiliza para satisfacer los derechos de la población, por lo que en cumplimiento de su deber se encuentra obligada tanto a proteger a los sectores vulnerables, como a mediar en las relaciones laborales o a dirimir los conflictos que se susciten entre los diversos actores sociales. Por ello, se extiende hacia los tres poderes de gobierno gracias a acciones cuya esencia es administrativa, legislativa y jurisdiccional. Consecuentemente, replicando conceptos vertidos por Cassagne (2010), es correcto afirmar que la administración pública no solo se define por la actividad del poder ejecutivo, sino que deben ser adicionadas las respectivas a los poderes legislativo y judicial.

El estudio de lo requerido para el ejercicio de una eficaz administración de justicia, como parte integrante de la administración pública, no debe dejar de lado el análisis del poder. El presente documento se adhiere a las reflexiones de Cassagne (2010) al considerar que el poder es único, pero se encuentra distribuido entre los tres poderes de gobierno: "Si se parte de la unidad del poder del Estado puede aceptarse sólo una distribución de funciones en órganos diferentes pero nunca una separación que opere, con límites precisos y definitivos, una delimitación absoluta de las funciones" (p. 72).

Entonces, las reflexiones respecto de la administración pública ineludiblemente deben contextualizarse. Tal como explicita Waldo (1948), su carácter público contiene dos lógicas diversas: la primera se corresponde con la voluntad popular, que sitúa a los mandatarios en los cargos ejecutivos para que tomen las decisiones de gobierno; la segunda se vincula con la ejecución de tales decisiones por intermedio de mandos técnicos. En cualquier caso, lo mencionado alude a la identificación de los técnicos y los políticos, dos actores diversos que se desempeñan bajo una guía de intereses y lógicas mayormente diferentes. El autor, en su libro The Administrative State. A Study of the Political Theory of American Public Adminsitration, afirma que si no existe una saludable relación entre la política y la administración, los escenarios resultantes oscilarán entre una total politización de esta última o una parálisis gubernamental. Explicita que:

El problema, entonces, es tener el control "necesario" de la administración por parte de la política, sin tener demasiado. Esto 
se puede lograr "reconociendo un grado de independencia en las autoridades administrativas como en las judiciales y cultivando una opinión pública sensata.

$[\ldots]$

El hecho es [...] que hay una gran parte de la administración que no está conectada con la política, que debería ser relevada en gran medida, si no en conjunto, del control de los cuerpos políticos. No está relacionado con la política porque abarca campos de actividad semicientífica, cuasijudicial y cuasicomercial o comercial. (Waldo, 1948, p. 109)

En la misma línea, pero a través de una mirada que se posa específicamente sobre la administración de justicia y las presiones que pudiera sufrir, Rebecca Bill Chávez (2007) argumenta que:

Las prácticas informales que permiten a los presidentes nombrar y remover a los jueces sin interferencia dan forma a la estructura de incentivos de tal manera que los jueces no se oponen a desafiar al ejecutivo. Cuando los jueces son castigados por intentar limitar las prerrogativas de los ejecutivos, el presidente ejerce fácilmente el control de la judicatura. (p. 34)

En una aproximación al núcleo del documento, se sostiene entonces que es necesario encontrar una correcta simbiosis entre la administración pública y la división de poderes a efectos de lograr un buen gobierno. El poder judicial es la última garantía de los ciudadanos ante el avasallamiento de sus derechos: si no hay justicia, no hay república. La justicia, tal como la define Cassagne al hablar de Tomás de Aquino, es un hábito mediante el cual cada uno tiene garantizados sus derechos.

La Justicia -que constituye una virtud superior- ha sido definida (sin variar fundamentalmente las clásicas concepciones de Ulpiano y de Aristóteles) como el "hábito según el cual uno, con constante y perpetua voluntad, da a cada cual su derecho". (2010, p. 109) 
De manera similar, refiriendo a ella, J. Rawlls manifiesta que:

La regla correcta, tal y como es definida por las instituciones, es regularmente observada y adecuadamente interpretada por las autoridades. A esta administración imparcial y congruente de las leyes e instituciones, cualesquiera que sean sus principios sustantivos, podemos llamarla justicia formal. (Rawlls, 1995, p. 65).

Por lo que resulta como requisito necesario para la prestación de la justicia una correcta administración. En su búsqueda, el presente documento analizará las modificaciones normativas que recayeron sobre el Consejo de la Magistratura de la República Argentina. La hipótesis que se plantea esgrime que fueron perjudiciales por permitir una injerencia política en su administración. En la búsqueda de fortalecer institucionalmente al organismo, recuperando la democracia, se realizará aquí un estudio comparativo de las normas que han modificado sus características sustanciales.

\section{Breve historia del poder judicial de la República Argentina}

Para finales del siglo XX, Argentina formó parte de una región que en términos similares se vio afectada por irrupciones a los órdenes constitucionales debido a repúblicas que no encontraron un equilibrio confiable en sus poderes de gobierno. La política halló la forma de penetrar la esfera judicial, convirtiendo a sus más encumbrados estratos en una arena de discusión partidaria. $\mathrm{Al}$ existir gobiernos civiles permeables a tales acontecimientos, no sorprende que las fuerzas castrenses también lo fueran. México resultó la excepción: sus gobiernos alcanzaron una adecuada sintonía republicana; Perú y Bolivia prácticamente carecieron de supremas cortes, dando la impresión de ser anexos de sendos poderes ejecutivos; Uruguay, Chile y Brasil construyeron cierto prestigio judicial que dilapidaron sus sangrientos golpes de Estado; Colombia y Venezuela impartieron justicia a través de distribuciones político-prebendarías de los cargos pertenecientes a las élites judiciales (Gargarella, 1997, p. 972); la República Argentina tal vez 
no fue tan republicana: desde la década del 30 hasta el presente, la historia reflejó en mayor o menor medida la influencia que el poder ejecutivo, en oportunidades democrático y en otras de facto, tuvo sobre el poder judicial. En por lo menos ocho oportunidades, el número o los nombramientos de los ministros de la Suprema Corte de Justicia de la Nación fueron alterados. Años como 1947, 1955, 1958, 1960, 1966, 1973, 1976, 1983 y 1990¹ determinaron modificaciones en la composición e integración del cuerpo con miras a conseguir mayorías funcionales. Las veces que la política no fue la responsable de maniatar a la justicia, lo hicieron los golpes de estado, que en oportunidades fueron inclusive beneficiados a partir de lo que se denominó como "la doctrina de facto".

Los hechos mencionados dan cuenta de la flexibilidad del máximo tribunal, aunque no debió ser; las frecuentes alteraciones que sufrió evidenciaron su maleabilidad, presente en igual o mayor medida en los juzgados inferiores. No resulta ilógico, entonces, que la ciudadanía no estuviese conforme con la prestación de la justicia recibida. En términos analíticos, no sorprende tal consideración porque el proceso de selección (descontando los mandatos dictatoriales), sanción y destitución de magistrados, poseía una elevada politización. Se iniciaba con la aparición de alguna vacante, acto seguido el presidente de la República proponía a la comisión de acuerdos del Senado el pliego de su candidato. Emitido el dictamen, el pleno de la cámara aprobaba la(s) designación(es) en los juzgados mediante una mayoría simple. En síntesis, lo que primaba realmente era la representatividad política que las fuerzas ejercían en el congreso. Una mayoría simplificaba la ecuación, mientras una minoría obligatoriamente debía ofrecer algo a cambio ante la necesidad de contar con el apoyo de una fuerza opositora en la aprobación del pliego de algún candidato postulado para asumir en las magistraturas disponibles. La relación de la justicia y la política era evidente.

Las elecciones libres que reabrieron la instancia democrática de gobierno otorgaron una cuota mayor de confianza a las instituciones: la justicia no se vio exenta de aquel fenómeno. El

1 Para más información, véase https://www.csjn.gov.ar/institucional/historia-de-lacorte-suprema/listado-historico-de-ministros 
Cuadro 1 explica empíricamente la cuestión, reflejando los bajos niveles de confiabilidad que el poder judicial ofrecía.

\begin{tabular}{|c|c|c|c|c|}
\hline & \multicolumn{4}{|c|}{ Mes/Año } \\
\hline Confiabilidad & $7 / 90$ & $4 / 91$ & $3 / 92$ & $4 / 93$ \\
\hline Positiva & 20,3 & 22,2 & 22,8 & 12,1 \\
\hline Regular & 41,4 & 40,2 & 40,2 & 30,7 \\
\hline Negativa & 28,9 & 33,2 & 28,4 & 49,6 \\
\hline No Sabe & 9,5 & 4,4 & 7,7 & 0,2 \\
\hline
\end{tabular}

Cuadro 1. Evolución de la imagen del poder judicial Fuente: Smulovitz C. (1995).

La reforma constitucional que vivió la República de Argentina durante el año 1994 halló entre sus objetivos fortalecer la independencia judicial; el instituto introducido para tal fin fue el Consejo de la Magistratura. Como se establecieron parámetros de orden general que no alcanzaron a delinear taxativamente sus características, su funcionamiento concreto tuvo lugar casi cuatro años después, gracias a la sanción de la Ley 24.937; en el artículo 114 de la Constitución argentina se dejó para una futura ley especial la composición del plenario del flamante organismo, entre otras cuestiones. Debido a ello, los nombramientos y destituciones de magistrados continuaron, hasta entrado el año 1998, funcionando en la forma previa y de manera más politizada que la propuesta. De igual modo, las sanciones permanecieron en la órbita de la Corte Suprema acompañadas por la facultad reglamentaria y la administración de los recursos presupuestarios.

\begin{tabular}{|c|c|c|c|c|c|c|c|c|c|}
\hline Confianza & 1995 & 1996 & 1997 & 1998 & 2000 & 2001 & 2002 & 2003 & 2004 \\
\hline $\begin{array}{c}\text { Nula o } \\
\text { baja }\end{array}$ & $33,6 \%$ & $23,1 \%$ & $20,5 \%$ & $19,9 \%$ & $27,0 \%$ & $20,5 \%$ & $8,7 \%$ & $16,2 \%$ & $26,2 \%$ \\
\hline $\mathrm{ns} / \mathrm{nc}$ & $62,1 \%$ & $72,4 \%$ & $75,1 \%$ & $78,4 \%$ & $67,6 \%$ & $77,0 \%$ & $90,3 \%$ & $81,2 \%$ & $72,4 \%$ \\
\hline & $4,4 \%$ & $4,5 \%$ & $4,2 \%$ & $1,9 \%$ & $5,6 \%$ & $2,5 \%$ & $1,0 \%$ & $2,6 \%$ & $1,4 \%$ \\
\hline
\end{tabular}

Cuadro 2. Porcentaje de confianza en la justicia argentina 1995-2004 Fuente: Smulovitz C. (2008).

El análisis del origen, desarrollo y final de la totalidad del proceso en el que se vio involucrado el Consejo de la Magistratura de la República Argentina permitirá reflexionar acerca de la relación entre mayorías, instituciones, administración de justicia 
y republicanismo. Todo ello derivará, sin ninguna duda, en una profundización de nuestro sistema democrático.

\section{El Consejo de la Magistratura}

La historia reciente de la República Argentina estuvo signada por vaivenes democráticos y quiebres constitucionales. El retorno de la democracia devolvió al país la capacidad, a través de la voluntad popular, de instalar a las autoridades electas y estas a los funcionarios encargados de impulsar el Gobierno. Desde la década del 30 hasta el presente, la historia reflejó en mayor o menor medida la influencia que el poder ejecutivo, en oportunidades democrático y en otras de facto, tuvo sobre ella.

La necesidad de devolver legitimidad a los magistrados requirió de un andamiaje institucional que posibilitara un alejamiento o intromisión del poder político en la órbita del poder judicial y garantizara una efectiva administración; el nombramiento de los candidatos de mayor aptitud, de forma paralela a la supervisión de la discrecionalidad de aquellos que se apartaran del deber, sin atentar contra la garantía constitucional respetuosa de la continuidad de los magistrados en sus cargos mientras ejercieran la buena conducta, debía institucionalizarse. En caso de no ejercerla, la institución debía ofrecer la correspondiente sanción o destitución.

La coyuntura política de los años finales de la primera presidencia de Carlos Menem fue intensa: las intenciones reelectorales del Partido Justicialista requerían de una reforma constitucional que no podría llevarse a cabo sin el acompañamiento de la Unión Cívica Radical. Esta avizoraba una derrota electoral, pero se encontraba interesada en establecer mecanismos de control al exacerbado presidencialismo con el que contaba (y cuenta actualmente) el país. Tal contexto puede enmarcarse en antesalas de reformas constitucionales donde las fuerzas políticas negocian de acuerdo a sus expectativas, tal como lo explica Negretto (2001): "los que se vislumbran ganadores tenderán a concentrar el poder mientras los menos optimistas querrán dispersarlo" (p. 416). A través de instituciones como la Jefatura de Gabinete de Ministros, el aumento de la representación de las minorías en la Cámara de Senadores (reforzando el carácter federal de la Nación) y la 
creación del Consejo de la Magistratura para restringir el avance político sobre la justicia, la Unión Cívica Radical supo que podría reforzar su rol de contralor. La discusión entablada en el seno de la comisión constituyente que abordó lo que se denominó como "núcleo de coincidencias básicas" durante los tiempos de la reforma constitucional, culminó - entre otras- con la concreción de mutuas intenciones partidarias.

El Consejo de la Magistratura es un organismo vital que halla su origen en el viejo continente y data de la segunda mitad del siglo XX. Ante los abusos producidos por los autoritarismos europeos, los constitucionalistas continentales, por intermedio del Consejo, impusieron ciertos límites en tiempos de posguerra.

Al momento de su creación en Argentina, tuvo lugar un profundo debate entre los convencionales Constituyentes que reflejó mayormente respaldos y en menor medida críticas. Ambas posiciones diferían respecto a la funcionalidad que el organismo tendría al insertarse en un régimen republicano. Quienes impulsaban la negativa criticaban, en algunos casos, que el Consejo de la Magistratura provenía de los parlamentarismos europeos donde la estructura de dichos regímenes era diferente al presidencialismo del país. Otros tantos estaban de acuerdo con la idea en bruto de la incorporación del organismo, pero sus reparos aparecían en la delegación de facultades que el proyecto de mayoría le otorgaba; como consideraban que ello no solo no fortalecía al poder judicial, sino que lo debilitaba, decidieron no acompañar con su voto. En contraposición, los que impulsaban la positiva, apoyaron su instauración argumentando que tal institución no interfería con la división de poderes ni debilitaba al poder judicial. El Consejo absorbería funciones de los tres poderes de gobierno, siendo responsable de seleccionar a los postulantes a las magistraturas inferiores mediante concursos públicos, elevar al poder ejecutivo las ternas de magistrados a fines de ocupar las magistraturas vacantes (tarea realizada con anterioridad por el presidente de la República), administrar la totalidad de los recursos judiciales y disciplinar a los magistrados que incurrieran en faltas, iniciando los procesos que derivarían en sanciones o en su destitución. Ambas funciones, correlativamente, eran ejercidas con anterioridad por los poderes judicial y legislativo. Su relevancia, establecida en la Constitución argentina, obligó a que la ley que lo creara fuera aprobada por una 
mayoría absoluta de los miembros de cada cámara; el equilibrio que yacería en su seno, resguardado por actores tales como la justicia, la política, los colegios de abogados y la participación de académicos sería esencial para cumplir con sus funciones. El artículo 114 le dio origen a este Consejo².

La solución implementada abriría otra serie de interrogantes: el Consejo de la Magistratura no obtuvo su composición ni tampoco la reglamentación de sus procesos disciplinarios ni de elección y sustitución de sus integrantes. Los apremiantes tiempos en los que la reforma constitucional se erigió, con sus inherentes pujas políticas, impidieron avanzar en los consensos requeridos. La configuración de la representación plural que compondría al organismo y brindaría resguardos institucionales a los procesos de toma de decisión sobre la administración de justicia quedó disminuida en el ordenamiento jerárquico, de modo tal que debió ser regulada gracias a la decisión de la mayoría absoluta de ambas cámaras del Congreso. El acuerdo alcanzado que posibilitó la reforma constitucional dejó a las mayorías ocasionales la determinación de las características más relevantes del Consejo de la Magistratura. A pesar de que la Convención Constituyente instó a la sanción de la ley regulatoria en no más de trescientos sesenta días, fueron la pérdida de la mayoría parlamentaria del Partido Justicialista en el año 1997, y sus previsiones respecto del futuro político que le avizoraba, las que finalmente permitieron dicha determinación. Así, cuestiones de índole estructural que requerían poderosos anclajes quedaron desprotegidas y supeditadas a la dinámica política.

\footnotetext{
2 “Artículo 114. El Consejo de la Magistratura, regulado por una ley especial sancionada por la mayoría absoluta de la totalidad de los miembros de cada Cámara, tendrá a su cargo la selección de los magistrados y la administración del Poder Judicial. El Consejo será integrado periódicamente de modo que se procure el equilibrio entre la representación de los órganos políticos resultantes de la elección popular, de los jueces de todas las instancias y de los abogados de la matrícula federal. Será integrado, asimismo, por otras personas del ámbito académico y científico, en el número y la forma que indique la ley. Serán sus atribuciones: 1. Seleccionar mediante concursos públicos los postulantes a las magistraturas inferiores. 2. Emitir propuestas en ternas vinculantes, para el nombramiento de los magistrados de los tribunales inferiores. 3. Administrar los recursos y ejecutar el presupuesto que la ley asigne a la administración de justicia. 4. Ejercer facultades disciplinarias sobre magistrados. 5. Decidir la apertura del procedimiento de remoción de magistrados, en su caso ordenar la suspensión, y formular la acusación correspondiente. 6. Dictar los reglamentos relacionados con la organización judicial y todos aquellos que sean necesarios para asegurar la independencia de los jueces y la eficaz prestación de los servicios de justicia” (Escuela Judicial, 2010).
} 
La Ley 24.937 estableció una composición de veinte representantes para el plenario de la institución; la imposición de dicho número no fue azarosa. Las decisiones que el organismo debía encarar, bajo el resguardo institucional normado, se fundaban obligatoriamente en el diálogo y la negociación, sanos componentes democráticos prudentemente establecidos en un diseño institucional que abogó, precisamente, por alcanzar una mejora en el ejercicio de la administración de justicia. La cantidad de miembros designados, respectivos a los distintos actores, respetaba un equilibrio plural que conducía sin excepción a lograr un consenso mayoritario. Ante su ausencia, gracias una presencia desproporcionada de cualquiera de los actores participes del organismo en cuestión, el resultado implicaría un desequilibrio perjudicial y nocivo en el marco institucional requerido para desempeñar una imparcial administración de justicia. Un Consejo desequilibrado, compuesto de forma inequitativa, pone en riesgo la independencia judicial y la administración de una justicia plena, pues una justicia parcial no es justicia. A continuación se detallarán los preceptos estructurales del Consejo de la Magistratura establecidos por la Ley 24.937:

\begin{tabular}{|c|c|}
\hline Composición & $\begin{array}{l}20 \text { Miembros: (1) presidente de la CSJN, (4) jueces del poder judicial de la } \\
\text { Nación, (8) legisladores: (4) pertenecientes a la HCDN y (4) al Senado, (4) } \\
\text { representantes de los abogados de la matrícula federal, (1) representante del } \\
\text { poder ejecutivo, (2) representantes del ámbito científico }{ }^{3} \text {. }\end{array}$ \\
\hline Comi & $\begin{array}{l}\text { De selección de magistrados y escuela judicial, de disciplina, de acusación, y } \\
\text { de administración y financiera }\end{array}$ \\
\hline $\begin{array}{l}\text { Atrib } \\
\text { del } P\end{array}$ & $\begin{array}{l}\text { Dictar los reglamentos referidos a la organización judicial; designar a los } \\
\text { miembros de las comisiones por una mayoría de dos tercios de los presentes; } \\
\text { decidir la apertura del procedimiento de remoción por una mayoría de dos } \\
\text { tercios de los presentes (y restituirlos en caso de corresponder); aprobar los } \\
\text { concursos y remitir al poder ejecutivo las ternas vinculantes de candidatos a } \\
\text { magistrados (mayoría de dos tercios de los presentes); aplicar las sanciones a } \\
\text { los magistrados propuestas por la Comisión de Disciplina por el voto de dos } \\
\text { tercios de los miembros presentes. }\end{array}$ \\
\hline Qu & $\begin{array}{c}\text { Doce miembros }{ }^{4} \text {. La toma de decisiones se lleva a cabo mediante una mayoría } \\
\text { absoluta de los presentes salvo indicaciones especiales. }\end{array}$ \\
\hline $\begin{array}{l}\text { Jurado de } \\
\text { Enjuiciamiento }\end{array}$ & $\begin{array}{l}\text { Integrado por nueve miembros: } 3 \text { jueces - un ministro de la CSJN y dos jueces } \\
\text { de cámara-, tres legisladores -dos pertenecientes al senado representantes } \\
\text { en representación de la mayoría y primer minoría, y el restante, miembro de } \\
\text { la Cámara de Diputados elegido por mayoría de votos-, y tres abogados de } \\
\text { la matricula federal. Dos pertenecientes a la FACA (por lo menos uno debe } \\
\text { representar a la matrícula del interior) y el restante al Colegio de Abogados de } \\
\text { la Capital Federal. }\end{array}$ \\
\hline
\end{tabular}

Cuadro 3. Características estructurales y de funcionamiento del Consejo de la Magistratura de la República argentina según la Ley 24.937

Fuente: Elaboración propia. 
Tal como lo refleja el cuadro, la norma instruyó el funcionamiento del Consejo de la Magistratura y su estructura de cuatro comisiones: Selección de Magistrados y Escuela Judicial, Disciplina, Acusación, y Administración y Financiera; también estipuló la composición que cada una de las comisiones. De forma dual, indicó y sugirió la presencia de determinados actores en las diversas comisiones: en la de Selección y Escuela Judicial, por intermedio del artículo $13^{5}$ determinó la presencia de representantes de los miembros de la esfera académico-científica y sugirió la de los abogados. El artículo $14^{6}$ hizo lo propio con la comisión de Disciplina, indicando preferentemente la presencia de los representantes del sector judicial y legislativo. La Comisión de Administración y Financiera, de acuerdo al artículo $16^{7}$, se integraría preferencialmente por los representantes de los jueces.

\section{A. Primera modificación de la Ley 24.937: Ley 26.080}

El primer desequilibrio se debió a la sanción de la Ley 26.080. La modificación sancionada por ambas cámaras del Congreso de la República Argentina no se condijo con lo establecido por el segundo párrafo del artículo 114 de la Constitución. Los argumentos expuestos por los legisladores colisionaron contra los que fueron oportunamente esbozados al momento de la creación constitucional del Consejo de la Magistratura. El partido oficialista (Frente para la Victoria $^{8}$ ), apoyado por diputados como Juan Manuel Urtubey, Luis Cicogna, César Nora, Gerónimo Vargas Aignasse y el presidente de su bloque, Agustín Rossi, legitimó las modificaciones bajo la supuesta ineficiencia del organismo -producto de su particular pertenencia a regímenes parlamentarios-y la insuficiente participación de los referentes ligados a la representación popular, supuestamente subrepresentados en aquellos tiempos. Adicionó que el equilibrio no implicaba igualdad y que, por ambas razones,

\footnotetext{
3 El primer párrafo del artículo ${ }^{\circ} 2$, inciso 6 de la Ley 24.937 fueron corregidos y reemplazados por el artículo ${ }^{\circ} 1$ de la Ley 24.939 .

4 El artículo ${ }^{\circ} 9$ de la Ley $\mathrm{N}^{\circ} 24.937$ fue corregido por la Ley $\mathrm{N}^{\circ}$ 24.939, estableciendo un quórum de 12 miembros presentes.

$5 \quad$ El artículo 13 de la Ley 24.937 fue corregido por la Ley 24.939.

$6 \quad$ El artículo 14 de la Ley 24.937 fue corregido por la Ley 24.939.

$7 \quad$ El artículo 16 de la Ley 24.937 fue corregido por la Ley 24.939.

8 El Frente para la Victoria fue la denominación de la facción que condujo al Partido Justicialista.
} 
la mayoría de la fuerza política oficialista debía espejarse en el seno del Consejo de la Magistratura. El diputado Urtubey, en sintonía, manifestaba lo siguiente: "Estos siete años nos han demostrado, y es pacífico admitirlo, que el funcionamiento dista de ser el ideal” (Versión taquigráfica de la honorable Cámara de Diputados de la Nación, 2006).

Seguidamente, haciendo una interpretación forzosa, intentó esconder una sutil diferencia entre las implicaciones de contar con una mayoría numérica de los representantes del parlamento entendida como bloque político y una mayoría del interior, representante de una única fuerza política determinada.

En primer lugar, brindaré las razones por la cuales el bloque de la Unión Cívica Radical ha aceptado que la presentación no sea igualitaria, aunque sí equilibrada”. Esto tenía una fundamentación, que la da más adelante, al señalar: “Conviene tener en claro que un pueblo que elige una determinada legitimidad tiene que hacer prevalecer, siempre en términos republicanos, la legitimidad democrática, y los diputados y senadores que integran ese Consejo son los únicos que responden frente al pueblo argentino en las urnas, porque en los otros dos casos estamos en presencia de jueces que tienen estabilidad y forman parte de un sistema corporativo y autorreferente. (Versión taquigráfica de la honorable Cámara de Diputados de la Nación, 2006)

Complementando las argumentaciones como presidente del bloque de la primer minoría, el diputado Rossi finalizó expresándose de la siguiente manera:

Tenemos un sistema jurídico institucional que se referencia en determinadas normas e incorporamos un instituto que funciona en el sistema europeo. Es lógico que con estos antecedentes ese instituto sea perfectible mediante reformas como ésta y algunas otras que podrán hacerse en el futuro, si fuere necesario... 
Por algo los constituyentes de 1994 no pudieron definir un número de integrantes; por algo sugirieron el equilibrio y no la igualdad; por algo este Congreso tardó tres años en dictar la ley que reglamenta este instituto. (Versión taquigráfica de la honorable Cámara de Diputados de la Nación, 2006)

Con anterioridad al cierre de su discurso, la oposición criticó la inevitable modificación que procedería horas más tarde. La diputada más precisa, cuya alocución resultó ser la más completa, fue la de. Marcela Rodríguez ${ }^{9}$. Su participación en sendos ámbitos, poder legislativo y Consejo de la Magistratura, le permitió grandes ventajas discursivas. Refutando la ampliación del bloque político, aseveró que en realidad se reducían tales voces por perder dos miembros quedando en un número de seis bancas, y en relación a la legitimidad derivada de los resultados electorales, desnudó las concretas intenciones, al quitarle la representación a la segunda minoría, de empoderarse de dos de los tres legisladores. He aquí sus palabras textuales:

Efectivamente, cuando se discutió y sancionó el proyecto de creación del Consejo de la Magistratura nosotros avalamos la representación de la voluntad popular por intermedio de diputados y senadores, justamente por tratarse de un órgano contramayoritario y porque las voces de la sociedad tienen que ser expresadas. Ahora bien, este proyecto no respeta ese principio. De hecho, es muy claro: pasamos de tener ocho representantes de la voluntad popular a tener simplemente seis. Esto no significa fortalecer las voces de la sociedad, sino restar voces; en todo caso, se trata de fortalecer la representación del oficialismo, no la de todas las voces. (Versión taquigráfica de la honorable Cámara de Diputados de la Nación, 2006)<smiles>[CH]1[CH]C=C1</smiles>

Seguramente van a venir con el argumento de que el problema es que la mayoría queda sub-representada. Esto no es cierto. Sin 
ir más lejos, miremos lo que ocurre en esta Cámara. Dicen que la mayoría y la minoría tienen la misma representatividad de dos miembros. Pero en este momento la primera minoría ni siquiera tiene la mitad de la Cámara. Con el proyecto se llegaría a los dos tercios de la representación de esta Cámara en el Consejo. Eso es una sobrerrepresentación. (Versión taquigráfica de la honorable Cámara de Diputados de la Nación, 2006)

Justificó una demora prudente de la totalidad del proceso de selección de los potenciales magistrados dada la longitud del circuito burocrático: desde el surgimiento de una vacante, prosiguiendo con el llamado a concurso, las entrevistas de los jurados a los aspirantes, los plazos de impugnación, los exámenes psicotécnicos, hasta la conformación de las ternas, "no es ilógica una demora de prácticamente un año”, explicó. Agregó que la demora adicional era producida adrede por el oficialismo y se fundaba en la manipulación y alteración del orden de las ternas para cubrir los diversos juzgados. Sucede que no todos poseen la misma importancia.

La Ley 24.937 determinó la integración del Consejo de la Magistratura, como se describió con anterioridad, en un marco equilibrado que forzaba un amplio consenso para la toma de decisiones. La reducción del número de consejeros de 20 a 13 mermó la participación de distintos sectores sociales al tiempo que alteró su representación. El consenso, si bien no dejó de ser requerido, pasó a contener un actor que se ubicó por encima del resto gracias a la justificación de que la representación de la mayoría parlamentaria debía estar reflejada en el pleno del Consejo; argumento sumamente discutible.

Amén de que es perfectamente comprensible lo que el término "equilibrio" significa, existen infinitas concepciones acerca de lo que representa una composición acorde. Objetivamente, la integración regulada por la Ley inicial fue más equilibrada, en función de la representación de la totalidad de los actores intervinientes, que su sucesora. 


\begin{tabular}{|c|c|c|c|c|}
\hline Actor & $\begin{array}{c}\text { Ley } \\
24.937\end{array}$ & $\begin{array}{c}\text { Ley } \\
26.080\end{array}$ & $\begin{array}{c}\text { Porcentaje } \\
\text { de representación } \\
\text { inicial }\end{array}$ & $\begin{array}{c}\text { Porcentaje } \\
\text { modificado }\end{array}$ \\
\hline CSJN & 1 & 0 & $5 \%$ & $0 \%$ \\
\hline Rep. abogados & 4 & 2 & $20 \%$ & $15,38 \%$ \\
\hline Rep. jueces & 4 & 3 & $20 \%$ & \begin{tabular}{c}
$23,08 \%$ \\
\hline Rep. legisladores
\end{tabular} \\
\hline $\begin{array}{c}\text { Rep. total del } \\
\text { oficialismo }\end{array}$ & 5 & 6 & $\begin{array}{c}46,16 \% \\
\text { al oficialismo, con una } \\
\text { representación del } 20 \%)\end{array}$ & $\begin{array}{c}\text { oficialismon } \\
\text { representación } \\
\text { del } 30,77 \%)\end{array}$ \\
\hline Rep. científicos & 2 & 1 & $10 \%$ & $7.69 \%$ \\
\hline Rep. poder & 1 & 5 & $5 \%$ & $7.69 \%$ \\
\hline
\end{tabular}

Cuadro 4. Comparativo de la composición porcentual estamentaria del pleno del Consejo de la Magistratura de la República de Argentina Fuente: Elaboración propia

El impacto concreto se vislumbra en la morigeración de la participación de los diversos actores en los procesos de toma de decisión requeridos, con excepción de la de los jueces. La sumatoria de los porcentajes correspondientes a los representantes del oficialismo, independientemente del origen de su representación, asciende a un 38,46\% desde un $25 \%$ inicial. De acuerdo a lo visto, existen dos mayorías para ratificar la toma de decisiones: una absoluta y otra de dos tercios de los presentes. En los casos en los cuales las facultades del plenario se rigen de acuerdo a la primera de ellas, no existe posibilidad de una aprobación inconsulta que responda a los intereses del gobierno de turno sin que otro actor acompañe la moción; el 38,46\% es insuficiente, pues se necesita una cifra mayor del $50 \%$. Sin embargo, para las facultades en las que es requerida la segunda de las mayorías presentes en el Consejo de la Magistratura, existe un fortalecimiento de la posición oficialista, pues hay una instancia de veto antes inexistente: la suma superior al tercio porcentual que detenta, impide a los restantes actores impulsar cualquier tipo de acción sin su consentimiento. 
Si bien el oficialismo por sí solo no podrá actuar, los sectores opositores no podrán hacerlo sin su consenso debido a que, naturalmente, no tienen posibilidades fácticas de alcanzar el $66 \%$ necesario; únicamente alcanzan un $61,54 \%$. Todavía lo expuesto podría no terminar de ser claro: el ascenso de trece puntos porcentuales respecto del anterior $25 \%$ redundará en que las posibilidades de accionar del organismo que fuera creado como barrera de obstrucción de la política sobre la justicia sean nulas. El bloque oficialista tendría que ser dividido para que la oposición pueda accionar alguna de las facultades que requieren de la más significativa de las mayorías establecidas, que responden, lógicamente, a procesos más sensibles en lo concerniente al balance de poder. ${ }^{10}$

Avanzando en el análisis, se aprecia también la modificación en las comisiones que integran el organismo. La ley infraconstitucional que diera forma al Consejo (corregida por la Ley 24.939), como antes se mencionó, indicó la presencia de los distintos estamentos en las comisiones. Su sucesora fue más concreta: directamente impuso la cantidad de integrantes de los diversos actores que conformaría cada una de ellas.

Como se observa en los dos cuadros, en la gran mayoría de los casos el porcentaje de representación política se incrementa. Se da una particularidad en la transformación de las comisiones de Disciplina y Acusación: el primer comentario se dirige a observar el nuevo porcentaje final, que alcanza el 55\% desglosándose del $71 \%$ y $40 \%$ respectivos; en segundo lugar, el bloque político no deja de contar con una mayoría de más del $50 \%$ de la composición de la comisión. La comisión unificada, independientemente de la reducción del número de integrantes representantes de los diversos estamentos (salvo el representante del sector académico/científico), cuenta con un nuevo participante: el representante del poder ejecutivo. Amén de la reducción del número de plazas de los senadores y diputados, el

\footnotetext{
10 "Ley 26.080, artículo 3. Atribuciones del Plenario. El Consejo de la Magistratura reunido en sesión plenaria, tendrá las siguientes atribuciones: inc 7) Decidir la apertura del procedimiento de remoción de magistrados — previo dictamen de la Comisión de Disciplina y Acusación-, formular la acusación correspondiente ante el Jurado de Enjuiciamiento, y ordenar después, en su caso, la suspensión del magistrado, siempre que la misma se ejerza en forma posterior a la acusación del imputado. A tales fines se requerirá una mayoría de dos tercios de miembros presentes”. (InfoLEG, s. f.) "Ley 24.937, artículo 13. Comisión de Selección y Escuela Judicial - inc C) Procedimiento [...]El plenario deberá adoptar su decisión por mayoría de dos tercios de miembros presentes y la misma será irrecurrible" (InfoLEG, s. f.).
} 
oficialismo encuentra la manera de morigerar dicha pérdida a través de la incorporación de un miembro afín. Las restantes comisiones de Selección y Escuela de Magistrados, y de Administración y Financiera ven incrementada la participación del bloque político en su seno: en la primera de ellas se duplica, mientras en la segunda el alza asciende un $7 \%$, quedando en un $57 \%$.

\begin{tabular}{|c|c|c|}
\hline Comisiones & Ley 24.937 & Ley 26.080 \\
\hline $\begin{array}{c}\text { De selección de Magistrados y } \\
\text { Escuela Judicial }\end{array}$ & $\begin{array}{c}4 \text { abogados }-3 \text { jueces }- \\
2 \text { diputados }-2 \text { representantes } \\
\text { ACA/científico }-1 \\
\text { representantes P. E. }\end{array}$ & $\begin{array}{l}3 \text { jueces }-3 \text { diputados }-1 \text { P. E. } \\
-1 \text { académico/científico }\end{array}$ \\
\hline De Disciplina & $\begin{array}{c}4 \text { senadores }-4 \text { jueces }-1 \\
\text { abogado }-1 \text { rep. académico/ } \\
\text { científico }\end{array}$ & \multirow{2}{*}{$\begin{array}{c}\text { (Unificación Disciplina y } \\
\text { Acusación) } 1 \text { rep. federal } \\
\text { abogados }-2 \text { senadores }-2 \\
\text { diputados }-2 \text { jueces }-1 \\
\text { académico/científico }-1 \text { P. E. }\end{array}$} \\
\hline De Acusación & $\begin{array}{c}4 \text { diputados }-2 \text { abogados }- \\
1 \text { senador }\end{array}$ & \\
\hline $\begin{array}{l}\text { De Administración y } \\
\text { Financiera }\end{array}$ & $\begin{array}{c}\text { jueces }-3 \text { senadores }-2 \\
\text { diputados }-1 \text { abogados }-1 \\
\text { rep. p.e }-1 \text { rep. académico/ } \\
\text { científico }\end{array}$ & $\begin{array}{c}2 \text { diputados }-1 \text { senador }-2 \\
\text { jueces }-1 \text { federal abogados } \\
-1 \text { P. E. }\end{array}$ \\
\hline De Reglamentación & ------- & $\begin{array}{c}2 \text { jueces }-1 \text { diputado }-1 \\
\text { senador }-1 \text { abogado }-1 \\
\text { académico/científico }\end{array}$ \\
\hline Jurado de Enjuiciamiento & $\begin{array}{c}3 \text { jueces - } 3 \text { legisladores ( } 2 \\
\text { senadores, } 1 \text { por la mayoría y } \\
\text { otro por la primera minoría y } \\
\text { un diputado) }-3 \text { abogados }\end{array}$ & $\begin{array}{c}2 \text { jueces }-4 \text { legisladores ( } 2 \\
\text { senadores y } 2 \text { diputados) }-1 \\
\text { abogado }\end{array}$ \\
\hline
\end{tabular}

Cuadro 5. Integración de las Comisiones del Consejo de la Magistratura de la República Argentina según las Leyes 24.937 y 26.080

Fuente: Elaboración propia.

\begin{tabular}{|c|c|c|}
\hline Comisiones & $\begin{array}{c}\text { Ley 24. 937: \% Estamento } \\
\text { Político }\end{array}$ & $\begin{array}{c}\text { Ley 26.080: \% Estamento } \\
\text { Político }\end{array}$ \\
\hline $\begin{array}{c}\text { De selección de Magistrados y } \\
\text { Escuela Judicial }\end{array}$ & $\begin{array}{l}12 \text { miembros: } 3 \text { bloque político } \\
25 \% \text { ( } 2 \text { diputados + } 1 \text { P. E.) }\end{array}$ & $\begin{array}{l}8 \text { miembros: } 4 \text { bloque político } \\
50 \% \text { (3 diputados + } 1 \text { P. E.) }\end{array}$ \\
\hline De Disciplina & $\begin{array}{c}10 \text { miembros: } 4 \text { bloque político } \\
40 \% \text { ( } 4 \text { senadores) }\end{array}$ & \multirow{2}{*}{$\begin{array}{c}9 \text { miembros: } 5 \text { bloque político } \\
55.55 \% \text { ( } 2 \text { senadores }+2 \\
\text { diputados }+1 \text { P. E. })\end{array}$} \\
\hline De Acusación & $\begin{array}{c}7 \text { Miembros: } 5 \text { Bloque Político } \\
71.43 \% \text { (4 Diputados }+1 \\
\text { Senador) }\end{array}$ & \\
\hline $\begin{array}{l}\text { De Administración y } \\
\text { Financiera }\end{array}$ & $\begin{array}{c}12 \text { miembros: } 6 \text { bloque } \\
\text { político } 50 \% \text { ( } 3 \text { senadores }+2 \\
\text { diputados }+1 \text { P.E) }\end{array}$ & $\begin{array}{c}7 \text { miembros: } 4 \text { bloque político } \\
57.14 \% \text { ( } 2 \text { diputados }+1 \\
\text { senador }+1 \text { P.E) }\end{array}$ \\
\hline De Reglamentación & ------ & $\begin{array}{l}6 \text { miembros: } 2 \text { bloque político } \\
33 \% \text { (1 diputado }+1 \text { senador) }\end{array}$ \\
\hline Jurado de Enjuiciamiento & $\begin{array}{c}9 \text { miembros: } 3 \text { bloque político } \\
33 \% \text { (3 legisladores) }\end{array}$ & $\begin{array}{c}7 \text { miembros: } 4 \text { bloque político } \\
57.14 \% \text { (4 legisladores) }\end{array}$ \\
\hline
\end{tabular}

Cuadro 6. Comparativo de la representación porcentual del estamento político en las comisiones del Consejo de la Magistratura de la República Argentina según las leyes 24.937 y 26.080 Fuente: Elaboración propia. 
El Jurado de Enjuiciamiento no solo no queda ajeno al fenómeno detallado, sino que ve aumentada la participación política en un significativo $25 \%$. No hace falta mencionar las implicancias de ello, pues su función es la de "juzgar a los jueces de los tribunales inferiores de la Nación” (Justia Argentina, s. f.). Partiendo de una composición de nueve integrantes, repartida en fragmentos igualitarios de tres miembros cada uno, se termina en una de siete posibilitada por la disminución de uno de los miembros vinculados a los magistrados y otra de dos miembros correspondiente al cuerpo de abogados, conservando cada uno de ellos solo una plaza.

Hay un aspecto que se desprende del presente análisis: el incremento de la participación del sector político en general, y del oficialismo en particular, en la toma de decisiones, antagónicamente produce una merma en las participaciones de los restantes actores. Como se parte de pisos mayores al $50 \%$ de representación en casi la totalidad de las comisiones (a excepción de la de Reglamentación) y considerando que la toma de decisiones se alcanza en algunos casos por mayoría absoluta y en otros gracias a una de dos tercios de los presentes, aquella, con posterioridad a la modificación, requiere de la participación de una cantidad menor de decisores. El consenso requerido establecido por la Ley 24.937, compuesto por una cantidad de actores, ya no requiere de dicha diversidad. La Ley 26.080 reduce el número de participantes en el consenso que conlleva la toma de decisiones.

Tal modificación normativa, en términos de acumulación de poder político, fue brillante; las consecuencias ignoradas (adrede) fueron la vulneración institucional y un aumento de la influencia del bloque oficialista sobre la administración de justicia. Sucesivos discursos de legisladores pertenecientes a aquellas filas manifestaron, en defensa de la modificatoria, que el equilibrio no implicaba igualdad, por lo cual la reforma no resultaba atentatoria. Así lo expresó la diputada Cesar del Partido Justicialista:

Actualmente, en el Consejo de la Magistratura la mayoría está representada en igual número que la minoría; por lo tanto, la composición vigente lesiona el criterio de representación popular y vulnera el ejercicio del voto realizado por la ciudadanía. De los trece miembros, siete pertenecen a los órganos de representación popular y los seis restantes son académicos, abogados y jueces. 
Entonces, me pregunto: ¿hay o no equilibrio? Son siete frente a seis. Reitero: el equilibrio no es igualdad. (Versión taquigráfica de la honorable Cámara de Diputados de la Nación, 2006)

Así, lo que el presente texto busca es explicar que una desigualdad tolerable es la que no genera un desequilibrio de índole señalada. Es aceptable que varias consideraciones respecto a lo que es el equilibrio puedan emitirse, más el límite está en el establecimiento de un "poder hegemónico", que es lo que se consiguió mediante la Ley 26.080. Citando el caso de la Constitución de la Provincia de Santa Cruz, el diputado Kunz (2006), resalta que taxativamente se indicó que el Consejo de la magistratura debía respetar un equilibrio que evitara la hegemonía, por lo que al término equilibrio se le impuso tal condición adicional. Si bien el artículo 114 de la Constitución Nacional no hace explícitamente tal aclaración, el presente documento alude al espíritu de los convencionales que, implícitamente, buscaron tal efecto. En alusión a la modificación normativa, Chávez argumentó lo siguiente:

La reducción en el tamaño, sin embargo, podría conducir a la politización del consejo y representar un paso más allá de la independencia judicial. La nueva legislación aumentará la representación proporcional de los miembros de las ramas políticas; superarán en número a los profesionales y académicos. La legislación exige una reducción en el número combinado de abogados, jueces y académicos en 5, de 11 a 6 . El número de representantes de las ramas políticas se reducirá en solo 2, de 9 a 7. Por lo tanto, el equilibrio en el consejo se desplazará a favor de las ramas elegidas del gobierno. (2007, p. 42)

Por ejemplo, contémplese un escenario donde el poder ejecutivo haya obtenido una mayoría absoluta (o cercana a ella) en los comicios electorales. Con un dominio del parlamento, la conducción del poder ejecutivo y un poder hegemónico o de veto sobre el poder judicial, ¿cómo es posible dar cumplimiento al primero de los artículos de nuestra Constitución? Tal división de poderes resultaría en una falacia. En tal caso, no sería posible hablar de justicia. El rotundo avance de la política otorgaría absoluto poder al presidente de la Nación, configurando realmente, en términos 
aristotélicos, una tiranía o una demagogia, regímenes comprendidos entre las formas impuras de gobierno.

\section{B. Segunda modificación de la Ley 24.937: Ley 26.855}

La Ley 26.855 volvió a modificar artículos sustanciales reglamentarios de sendas misiones y funciones del Consejo de la Magistratura; los argumentos emitidos para su sanción refutaron a los de su predecesora, que parecieron quedar obsoletos: la cantidad de miembros volvió a ser aumentada y un concepto nuevo fue puesto en escena. La "democratización de la justicia” se utilizó como fundamento rector de la elección popular de los consejeros. Se sostuvo la necesidad de hacer partícipe a la ciudadanía en tal instancia electiva, olvidando -nuevamente- el escollo sustantivo de politizar un organismo vital a la hora de controlar a la fuerza mayoritaria. Resulta sencillo para los funcionarios justificar la elección de diversos cargos bajo el manto de la democracia. Si aquel régimen implica el gobierno del pueblo, ¿por qué este no podría elegir a sus representantes?

El 8 de mayo del 2013, dentro del recinto de la Cámara Alta del Congreso Nacional, el miembro informante de la mayoría ${ }^{11}$, senador Fuentes, hacía su alocución sobre los beneficios de la nueva iniciativa: el sostén argumental fue la profundización de la democracia a través de la lucha popular; la delegación en el pueblo de la elección directa de los consejeros, en desmedro de intereses de los tradicionales, y poderes concentrados, guardianes del status quo. Sin asumir la introducción de una bisagra institucional permisiva de la influencia proselitista, remitió a un déficit de origen democrático inherente al poder judicial para ser subsanado gracias a la elección de un padrón de veintidós millones de electores.

Las modificaciones producidas por la nueva ley prácticamente retrotrajeron el número de representantes a la cantidad de bancas inicial: diecinueve miembros integrarían el plenario. Tres jueces del poder judicial, tres representantes de los abogados de la matrícula federal, seis representantes del ámbito académico-científico, seis legisladores (en partes iguales de ambas cámaras) y el representante del poder ejecutivo. Nuevamente el estamento político se situó por

11 La fuerza política mayoritaria era el Frente para la Victoria. 
encima del tercio de los integrantes; un porcentaje del $36,84 \%$ pertenecía a la suma de los legisladores y el representante del poder ejecutivo; nuevamente volvieron a realizarse alteraciones en las mayorías requeridas para dar cumplimiento a las facultades propias del organismo y a la composición de las comisiones que lo integran. Ello fue logrado a través de los artículos 6 y 8 de la última norma:

\begin{tabular}{|c|c|c|}
\hline Facultad & Ley 26.080 & Ley 26.855 \\
\hline $\begin{array}{c}\text { Dictar reglamentos para designar a jueces } \\
\text { subrogantes (y designarlos) }\end{array}$ & Facultad ausente & Mayoría absoluta \\
\hline $\begin{array}{c}\text { Decidir la apertura del procedimiento de } \\
\text { remoción }\end{array}$ & Mayoría de 2/3 & Mayoría absoluta \\
\hline $\begin{array}{c}\text { Aceptación del plenario de la decisión de la } \\
\text { Comisión de Selección y Escuela Judicial }\end{array}$ & Mayoría de 2/3 & Mayoría absoluta. ${ }^{12}$ \\
\hline
\end{tabular}

Cuadro 7. Comparativo de las mayorías requeridas entre las Leyes 26.080 y 26.855

Fuente: Elaboración propia.

Respecto a la integración de las comisiones, a continuación se reflejan los números que estableció la norma ulterior:

\begin{tabular}{|c|c|c|c|c|}
\hline Comisiones & Ley 26.080 & Ley 26.855 & $\begin{array}{c}\text { \% Part. Política } \\
26.080\end{array}$ & $\begin{array}{c}\text { \% Part. Política } \\
26.080\end{array}$ \\
\hline $\begin{array}{l}\text { De selección de } \\
\text { Magistrados y } \\
\text { Escuela Judicial }\end{array}$ & $\begin{array}{c}3 \text { jueces }-3 \\
\text { diputados }-1 \mathrm{P} \text {. } \\
\text { E. }-1 \text { académico/ } \\
\text { científico }\end{array}$ & $\begin{array}{c}2 \text { jueces }-3 \\
\text { legisladores }-2 \\
\text { abogados }-3 \\
\text { académico/ } \\
\text { científico }-1 \mathrm{P} \text {. E. }\end{array}$ & $50 \%$ & $36.36 \%$ \\
\hline $\begin{array}{l}\text { De Disciplina y } \\
\text { Acusación }\end{array}$ & $\begin{array}{c}1 \text { federal } \\
\text { abogados }-2 \\
\text { senadores }-2 \\
\text { diputados }-2 \\
\text { jueces }-1 \\
\text { académico/ } \\
\text { científico }-1 \text { rep. } \\
\text { P. E. }\end{array}$ & $\begin{array}{c}2 \text { jueces }-3 \\
\text { legisladores }-2 \\
\text { abogados }-3 \\
\text { académico/ } \\
\text { científico }-1 \text { rep. } \\
\text { P. E. }\end{array}$ & $55.55 \%$ & $36.36 \%$ \\
\hline $\begin{array}{l}\text { De } \\
\text { Administración y } \\
\text { Financiera }\end{array}$ & $\begin{array}{c}2 \text { diputados }-1 \\
\text { senador }-2 \\
\text { jueces - } 1 \text { federal } \\
\text { abogados - } 1 \text { P. E. }\end{array}$ & $\begin{array}{c}2 \text { jueces }-2 \\
\text { legisladores }-1 \\
\text { abogado }-3 \\
\text { académico/ } \\
\text { científico }-1 \text { P. E. }\end{array}$ & $57.14 \%$ & $33 \%$ \\
\hline
\end{tabular}

12 Es sutil la modificación que se produce respecto del procedimiento de elevación de las ternas por parte de la comisión al plenario. Si se analiza la facultad expresamente establecida bajo las competencias del plenario del Consejo, en el artículo 7 de la Ley 24.937 , no modificado por la 26.080, se vislumbra en su inc. 7 que la aprobación de los concursos y la remisión de ternas requiere una mayoría absoluta. Contrariamente, el artículo 9 inc. C, en referencia a la conformación de las ternas, establece taxativamente que "el plenario deberá adoptar su decisión por mayoría absoluta del total de sus miembros y la misma será irrecurrible”. La ley anterior estipuló una mayoría de dos tercios. 


\begin{tabular}{|c|c|c|c|c|}
\hline Comisiones & Ley 26.080 & Ley 26.855 & $\begin{array}{c}\text { \% Part. Política } \\
26.080\end{array}$ & $\begin{array}{c}\text { \% Part. Política } \\
26.080\end{array}$ \\
\hline $\begin{array}{c}\text { De } \\
\text { Reglamentación }\end{array}$ & $\begin{array}{c}2 \text { jueces }-1 \\
\text { diputado - } 1 \\
\text { senador - } 1 \\
\text { abogado - } 1 \\
\text { académico/ } \\
\text { científico }\end{array}$ & $\begin{array}{c}2 \text { jueces }-3 \\
\text { legisladores }-1 \\
\text { abogado }-3 \\
\text { académico/ } \\
\text { científico }\end{array}$ & $33 \%$ & $33 \%$ \\
\hline $\begin{array}{c}\text { Jurado de } \\
\text { Enjuiciamiento }\end{array}$ & $\begin{array}{c}2 \text { jueces }-4 \\
\text { legisladores (2 } \\
\text { senadores y } 2 \\
\text { diputados) - } 1 \\
\text { abogado }\end{array}$ & $\begin{array}{c}\text { Sin } \\
\text { modificaciones }\end{array}$ & w57.14\% & $57.14 \%$ \\
\hline
\end{tabular}

Cuadro 8. Comparativo de la representación porcentual del estamento político en las comisiones del Consejo de la Magistratura según las leyes 26.080 y 26.855

Fuente: Elaboración propia.

La réplica no demoró en llegar. El senador Sanz, explicitó cuáles resultaban los principales inconvenientes de la iniciativa en tratamiento, de acuerdo a las consideraciones de la Unión Cívica Radical:

Son tres elementos que, en conjunto y de manera integrada -el número de miembros, la forma de elección y la mayoría, que es pasar de dos tercios a mitad más uno de la totalidad de los miembros-definen la discusión. Eso es lo que en el fondo se discute. Se han cambiado las reglas del juego. Se han cambiado las reglas por las que se manejaba el Consejo y, fruto de esos tres elementos tomados en conjunto, quien gana la elección va a manejar absolutamente el proceso de selección y destitución de jueces. (HCSN, 2013)

El incremento en el número de integrantes redujo la participación política en las comisiones y su respectivo porcentaje. En ambos casos, la representación inicial -como mínimo del $50 \%$-descendió a un 36,36\%. Tal reducción se podría concebir como positiva, pues conllevaría el aumento natural de los restantes consejeros, sin embargo no cumpliría dicho cometido. El artículo 4 de la norma transformó radicalmente la esencia del Consejo: su función ya no podría ser cumplida de acuerdo a lo establecido por la Constitución argentina. Retrotrayendo los tiempos al momento de su reforma, las intenciones y expresiones de los constituyentes justificaban la intromisión de un organismo para alivianar la 
influencia política sobre el poder judicial. Ello sería realizado gracias a una composición plurisectorial integrada por actores que no vinieran del mundo de la política. Esta alteración del origen de los sectores académicos, abogadiles y magistrales liga el accionar técnico a un vehículo político. ¿Qué es lo que se quiere representar con esto?: 1) que transformar un origen estrictamente técnico en uno político no solo no disminuye la participación política en los mencionados procesos, sino que al ser los partidos quienes eligen a los precandidatos de estos sectores, es posible que no se haga una selección de los mejores profesionales, pues culmina en la selección de profesionales que comulguen políticamente con los preceptos partidarios. Tal acción, nuevamente, introduce la politización en la justicia. 2) Que la elección de los miembros “apolíticos" se produzca por un electorado general que puede no estar técnicamente instruido en los campos en los que lo están estos actores, conlleva una morigeración del nivel técnico de los consejeros. Por ello, la representación comprendida a partir de los estamentos garantiza una mayor instrucción, resguardando el fin inicial del Consejo.

En el mismo orden de cosas, la reducción de las mayorías necesarias para realizar la apertura de los procedimientos de remoción y aprobación de las ternas hace que la disminución proporcional del estamento político no resulte en un beneficio, toda vez que el poder ejecutivo se encuentra más cercano a imponer su voluntad y la cantidad de actores necesarios para consensuar es menor. Ello significa que el poder ejecutivo deberá hacer menores esfuerzos para conseguir apoyos. La reducción en el número requerido de estamentos para establecer consensos en los procesos de nombramiento y destitución de jueces vuelve a reflejar el peso preponderante del oficialismo y su intromisión en la esfera judicial.

Al reflexionar respecto de lo acontecido, con miras a esclarecer lo que la República y la justicia necesitan para materializarse, es necesario hacer precisiones, pues cuando se habla de democracia, la referencia apunta a resaltar la elección popular de los funcionarios en un marco constitucional de derechos políticos, mas no del sistema ni de los mecanismos que la concretarán. En un Estado democrático, la elección popular de la totalidad de funcionarios que se desempeñan en las diversas órbitas estatales es inconveniente, tal es el caso de la justicia. el poder judicial no debe ser popular ni democrático; debe ser contramayoritario. 


\section{Conclusiones}

La mayoría construida por el oficialismo (propios más aliados) en las elecciones legislativas del 2005 le permitió sancionar la primera de las iniciativas que produciría alteraciones en el equilibrio del pleno del Consejo de la Magistratura y el proceso electoral del 2011 brindó al oficialismo una mayoría absoluta. El hecho de alzarse con un $53 \%$ de la totalidad de los votos le otorgó un número de escaños suficiente para sesionar sin la presencia de ninguna otra fuerza política opositora; el número de diputados conseguido lo facultó a detentar el quórum propio. A partir de ello, logró controlar los mecanismos legislativos de tal forma que el rol de la oposición quedó reducido meramente a la observación y a la manifestación de argumentos sin poder hacer valer su función de contralor.

Es preciso aclarar que aquella mayoría "automática"13 fue legítima; como consecuencia, el poder legislativo adoleció de la participación efectiva de las minorías, dado que los reglamentos que instituyen la conformación de las comisiones parlamentarias y la ausencia de determinados mecanismos, recortaron su accionar. Esta realidad vulneró el sistema de pesos y contrapesos, posibilitando la reforma del Consejo de la Magistratura y empobreciendo la calidad democrática que tiene lugar en el sistema presidencialista argentino, que asimismo cuenta con un ya fortalecido poder ejecutivo.

Escenarios de mayorías absolutas y fuertes doctrinas partidarias - como es el caso del Partido Justicialista- en los que prevalece la concentración del poder, ponen en jaque la columna vertebral del poder judicial. Este argumento es compartido por Chávez (2007) al manifestar que las mayorías políticas son cruciales para definir la independencia judicial. Según esta autora, el poder judicial es independiente cuando existe un equilibrio de poder entre al menos dos partidos políticos de fuerza relativamente similar, ninguno de los cuales está en condiciones de controlar monolíticamente las ramas ejecutiva y legislativa. Por el contrario, en situaciones de gobierno unificado y disciplina de partido, los presidentes pueden manipular el diseño institucional del poder judicial para evitar

13 El adjetivo se refiere a la certeza con la que el poder ejecutivo contaba respecto del cumplimiento de su voluntad por parte de los legisladores oficialistas. 
que actúe como un órgano de control, cambiando, por ejemplo, el proceso de designación y remoción de jueces o eliminando la representación de la oposición en las cortes.

Sendas modificaciones normativas dan cuenta de la fragilidad que detenta el Consejo de la Magistratura de la República argentina. Las reiteradas alteraciones tanto del diseño institucional, como del marco regulatorio ponen al descubierto la carencia de una férrea estructura que limite la discrecionalidad política y reflejan la presión que logró ejercer el oficialismo sobre el poder judicial. Consecuentemente, la prueba empírica también se vislumbra en el curioso accionar de la propia justicia en cuanto a los tiempos de resolución de los planteos efectuados en referencia a las Leyes 26.080 y 26.855. La lentitud en la consideración de la primera norma no se repitió en la segunda, pues esta requirió de un análisis urgente gracias a la proximidad de las elecciones que llevarían a los consejeros como candidatos. La dilación padecida en el tratamiento de la reducción del plenario del organismo (Ley 26.080) culminó su segunda instancia el 19 de noviembre del 2015. Considerando que su sanción se produjo a principios del año 2006, y rápidamente conllevó una acción judicial, la situación deja ver que existió un lapso sin resolución de prácticamente diez años. Dicha demora implicó profundos perjuicios a la administración de justicia: juzgados vacantes, jueces que debieron ser nombrados, destituidos o sancionados y jueces subrogantes que, en muchos de los casos, resultaron (y resultan) bastante más permeables, que los titulares. Diez años después, el fallo 29.053/2006 de los jueces de la Sala II de la Cámara Contenciosa Administrativa Federal, José Luis López Castiñeira y Luis María Márquez decretó la inconstitucionalidad del artículo primero de la Ley 26.080 que reducía la composición del consejo de veinte a trece miembros.

Respecto de la Ley que "democratizara la justicia”, agotada la primera instancia y debido al per saltum que solicitara el Gobierno, la Corte Suprema de Justicia falló el 18 de junio del 2013 declarando la inconstitucionalidad de varios de sus artículos.

La injerencia de la política sobre el poder judicial, posibilitada gracias a las modificaciones de las normas en cuestión, resultó atentatoria para el andamiaje institucional garante de una efectiva administración pública; ello equivale a argumentar que la vulneración institucional en la que se ha incurrido incide 
negativamente en la integración del Consejo de la Magistratura argentino, su administración y consecuentemente en los procesos de selección y destitución de magistrados, negando conjuntamente la autonomía constitucional que debiera estar garantizada en la práctica, así como una correcta administración de justicia.

Transcurrido el análisis propuesto, la conclusión respecto de la efectividad del artículo 114 continúa ausente: no ha sido posible de dilucidar, dada la falta de resolución del expediente 29.053/2006 -denunciante de la modificación de la composición inicial del plenario del Consejo establecida por la Ley 24.937- en la Corte Suprema de Justicia. Sería sencillo adjudicar culpas al Partido Justicialista, debido a que en gran medida se rehusó a delinear una composición constitucional numérica de los integrantes del pleno del Consejo de la Magistratura; también sería injusto hacerlo, pues no todos los representantes del Partido Radical consideraron lo contrario. Tampoco puede negarse que la introducción de un organismo de origen europeo, inserto en regímenes parlamentarios, conllevó dudas en relación a cómo se adaptaría al sistema presidencialista argentino.

La resolución definitiva de la Corte Suprema arrojará luz sobre el error o acierto del trazo general de principios alusivos al organismo en tiempos de la reforma constitucional y la consecuente necesidad de continuar su reglamentación por la vía legislativa; podría considerarse, asimismo, si la mayoría requerida para dicha reglamentación fue insuficiente. Se avizoran dos posibilidades: la declaración de inconstitucionalidad o la legitimidad. El primer resultado reflejaría un periodo de más de dos décadas de una administración de justicia injusta, ergo una vulneración de uno de los derechos esenciales que debiera haber garantizado el Estado; el segundo establecería un nuevo paradigma en la relación republicana entre poderes.

De acuerdo a la evidencia recolectada, este trabajo considera que las sucesivas reformas al Consejo de la Magistratura perjudicaron la administración de la justicia al permitir desbalances e intromisiones del poder político.

Reflexionar acerca de los actos propios de la mayoría, fundados sobre el principio de poder absoluto que reposa sobre ella y justificados democráticamente, contribuirá con la maduración institucional de tal régimen que, perfectible como 
es, sigue siendo la mejor alternativa para la implementación de la gestión gubernamental moderna. La mejora de los mecanismos institucionales tenderá a que cada individuo vea satisfecho el cumplimiento de sus derechos a través del correcto ejercicio de la administración pública.

\section{Referencias}

Alfonso, S. (31 de octubre de 2011). Todo sobre la Corte. Recuperado de http://todosobrelacorte.com/.

Cámara de Diputados de la Nación (22 de febrero de 2006). Versión Taquigráfica de la reunión 44 sesión extraordinaria $n^{\circ} 3$. Recuperado de http://www.hcdn.gov.ar/secparl/dtaqui/

Cassagne, J. (2010). Derecho Administrativo - Tomo I (9 ed.). Buenos Aires: Abeledo Perrot.

Caso "Rizzo, Jorge Gabriel (apoderado Lista 3 Gente de Derecho) c/ Poder Ejecutivo Nacional, ley 26.855, medida cautelar s/ acción de amparo" (2013). CSJN, Fallos 336:760. Recuperado de http://cjys.unpaz.edu.ar/ sites/default/files/Analisis\%20Jurisprudencial\%20CS\%20Parte\%20 general.pdf

Centro de Información Judicial (11 de junio de 2013). Resolución Rizzo, Jorge Gabriel (Apoderado Lista 3 'Gente de Derecho s/ Acción de Amparo c/ Poder Ejecutivo Nacional - Ley 26.855 - Medida Cautelar”. Expediente $N^{o}$ 3034/13. Recuperado de http://www.cij.gov.ar/nota-11636-Reformajudicial--fallos-de-la-jueza-federal-Maria-Servini-de-Cubria.html

Centro de Información Judicial (11 de junio de 2013). Resolución "Traboulsi, Carlos Lionel s/ Promueve Acción de Amparo c/ Poder Ejecutivo Nacional - Medida Cautelar". Expte. $N^{o}$ 3041/13. Recuperado de https://goo. $\mathrm{gl} / 7 \mathrm{UVGhX}$

Chávez, R. (2004). The The Appointment and Removal Process for Judges in Argentina: The Rol of Judicial Councils and Impeachment Juries in Promoting Judicial Independeca .Latin American Politics and Society, 49, 33-58.

Consejo de la Magistratura. Reglamento General del Consejo de la Magistratura. Recuperado de https://goo.gl/u2tHSH

Constitución Nacional de la República de Argentina. Recuperado de http:// www.infoleg.gob.ar/?page_id=63

Convención Nacional Constituyente (1 de agosto de 1994). Versión Taquigráfica $21^{a}$ Reunión - $3^{a}$ Sesión. Recuperado de https://goo.gl/ nCT8Yh 
Escuela Judicial (31 de octubre de 2010). Artículo 114 de la Constitución nacional. Recuperado de http://escuelajudicial.pjn.gov.ar/mod/ resource/view.php?id $=52$

Gargarella, R. (1997). Recientes reformas constitucionales en América Latina: una primera aproximación. Desarrollo Económico, 36, 971-990.

Justia Argentina (s. f.). Artículo 115 de la Constitución Nacional argentina. Recuperado de https://argentina.justia.com/federales/constitucionde-la-nacion-argentina/segunda-parte/titulo-primero/secciontercera/capitulo-primero/

Llanos, M. y Figueroa Schibber, C. (2008). La Participación de la Presidencia y el Senado en el nombramiento del Poder Judicial. Desarrollo Económico, 47, 607-637.

Negreto, L. G. (2001). Negociando los poderes del presidente: reforma y cambio constitucional en la Argentina. Desarrollo Económico, 41, 411-444.

Poder Judicial de la Nación. (19 de noviembre de 2015). Resolución "Colegio de Abogados de la Ciudad de Buenos Aires y otro c/E.N. - Ley 26.080 - Dto. $816 / 99$ y otros s/proceso de conocimiento - respecto del recurso interpuesto". Recuperado de https://goo.gl/YEq96c

Procuración General de la Nación (17 de junio de 2013). Dictamen Rizzo, Jorge Gabriel (apoderado lista 3 gente de dcho) s/ acción de amparo c/ Poder Ejecutivo Nacional -Ley 26.855-. Medida Cautelar. En Dictámenes de la Procuración General de la Nación. Recuperado de https://goo.gl/jCQp9n

Procuración General de la Nación (17 de junio de 2013). Dictamen Procuración General del Estado s/ Traboulsi Carlos Lionel s/ promueve acción de amparo c/ P. E. N. Medida Cautelar. En Dictámenes de la Procuración General de la Nación. Recuperado de https://goo.gl/jCQp9n

Rawlls, J. (1979/2006). Teoría de la Justicia (6 $6^{\text {a }}$ reimpresión). México: Fondo de Cultura Económica.

Smulovitz, C. (1995).El Poder Judicial en la Nueva Democracia Argentina. El trabajoso Parto de un Actor. Agora Cuaderno de Estudios Políticos, 2, $85-105$

Smulovitz, C. (2008). La política por otros medios. Judicialización y movilización legal en la Argentina. Desarrollo Económico, 48, 190/191, $287-305$.

Tocqueville, A. (2003). La democracia en América. Buenos Aires: Universidad de Buenos Aires. 